\title{
We will not Get Rid of Coronaviruses without Creating a True Sustainable Development Model
}

Luigi Antonio Pezone

Environmental and sustainable energy inventor, Italy

\author{
"Correspondence author \\ Luigi Antonio Pezone \\ Environmental and sustainable energy inventor \\ Italy
}

\begin{abstract}
If it is true that covid-19 comes from wild animals that have lost their natural habitat due to deforestation and large forest fires and savannas; if it is true that the mortality of those affected increases exponentially in the areas with higher percentages of fine dust, Nox, Sox, CO, in the atmosphere; if it is true that the most affected are the elderly, what does this have to do with the European call for startups dedicated to the Covid-19 emergency, which expired on 18 March, intended above all for small and medium-sized enterprises for innovative contributions useful for cope with any aspect of the emergency? The budget for this call is 164 million euros. What is this rain of millions on small and medium-sized enterprises? At most, they can develop some control and monitoring software for people who move around the area. This is already being done in China and Korea. Since we are late, we may also be able to import this software from these countries. Why, as Europeans, do we not focus on the real problem that affects the entire world development? Emerging countries, such as China and Korea, have made the mistake of copying our energy and purification solutions, even surpassing us by the amount of pollution produced. EUROPE should anticipate the immediate decarburization of energy, the modification of urban purification systems (we cannot continue to wait for the rains to reduce fine particles).
\end{abstract}

We also need to revolutionize global transportation systems. We cannot deforest forests to cross them with roads and railways that also have very high costs, only because we have not been able to develop a sustainable energy process that can add up the thrust of Newton and Lorentz and fly the means of transport over the forests and the savannas. Not only to fly over them without going through them, but also to put out the fires that are destroying these huge natural resources. We remember what happened in Australia in the summer of 2019. This means that we must completely change the way we produce fixed and mobile energy worldwide because air transport is even more polluting than thermal power plants, incinerators, and cannot stop on fire outbreaks because they keep in flight based on aerodynamic principles. If they slow down the speed of the flight to put out the fires, they collapse on the ground. But this problem can be overcome with interactive global linear motors that would add together the thrust of Newton and Lorentz. These can develop an infinite amount of energy without producing any pollution because the primary energy is extracted directly from the environment.
As described by myself in http://www.spawhe.eu/aerospaceand-submarine-transport-system-with-global-interactiveprimary-and-inductive-linear-motors/, http:/www.spawhe. eu/flying-and-floating-cars-with-interactive-global-linearmotors-and-thrust-of-newton-and-lorentz/

Why don't governments try these solutions? This certainly cannot be done by small businesses. The collaboration of governments and major world industries is needed, since my solutions of intellectual patents, to which world legislators do not even recognize the copyrights that are recognized even to those who write a simple song. Some emerging countries have overtaken the old industrialized countries in the development of computer software, which does not require large structural investments. Unfortunately, they have also surpassed them in the wrong plants, which require large structural investments Thermal, nuclear, hydroelectric, transport systems, energy distribution networks, purification systems. All these systems are uneconomical, inefficient and polluting, not being interactive, but as the countries that created them have not 
noticed, even the emerging ones have not noticed, which also in this case have passed the state of the art, but only in size. We are not talking about the current water and air purifiers. They are all to be scrapped, since in urban centers, the air is not purified at all and the water is purified with very high-energy costs tens of kilometers from urban centers, acidifying it.

A sustainable global project must be divided into many related projects that share the tasks, not the goal. World public bodies carry out tenders and single-issue, uncoordinated competitions. For this reason, in the SYNTHESIS OF DESCRIPTION (The complete description can be downloaded in pdf format from http://www.spawhe.eu/we-will-not-get-rid-of-coronaviruseswithout-creating-a-true-sustainable-development-model/), whole world we have environmental and energy plants arranged at random on the territories that carry out incomplete cycles and produce more damage than benefit. Current hydroelectric plants favor floods and droughts; heating systems promote air pollution, lung diseases and global warming; nuclear ones favor radioactive accidents; water purifiers produce acid water because they cannot alkalize them with current purification cycles. Environmental science does not include, for example, that an air conditioner can work by exchanging heat with the outside air or with a low enthalpy geothermal well. In the first case, it carries out a partial cycle that heats the planet and spreads the dust into the environment, in the second case it is inserted in a global cycle. Public authorities must impose a way to build air conditioners even if, apparently, the air conditioner costs less if it exchanges air for air. In reality, the global cycle is increasingly cheaper because it eliminates the external units of the air conditioners and the geothermal well itself, if built differently from the current geothermal wells, can also produce electricity, not only for air conditioning, but also for other energy functions. And urban depuratives, such as oxidation and alkalinization of water in mini limestone greenhouses. Just think that if we decarbonise the production of world energy and build purification plants by oxygenating and raising the water without fuel costs, we can even subtract $\mathrm{CO} 2$ from the environment by creating artificial rains on calcareous materials producing carbonates that go to the sea. If we also add to these systems the artificial welling that raises the carbonates solubilized to the ocean depths to the surface, we can slowly bring the oceans and the atmosphere back to the alkaline values existing before the industrial era, reforming the terrestrial and marine glaciers, lowering the water level and extracting from the sea more food than we currently produce from land crops.

Not knowing how to deal with environmental and health problems rationally, on the occasion of covid-19, the European Community is spending millions of euros on small and medium-sized enterprises to do the same things they are doing better than we do in China and Korea. Instead, they should encourage the creation of new small and medium-sized enterprises that produce interactive energy and purification, which would originally prevent the development of viruses such as coronaviruses and would also make them less dangerous for human health, having to spread without atmospheric dust,

\section{SOx, NOX, CO}

The United Nations, Europe and all world countries have ignored sustainable inventions and declined national, European, international patents, ignored open letters to all institutions. It would be enough to read from the bottom to the top, from the old home page to the new home page, the website http://www. spawhe.eu, to understand that this alternative development model, which would involve hundreds of thousands of small and medium-sized enterprises, has already been developed in essential details. In fact, since interactive energy does not need large thermal power plants, nuclear power plants, nor even distribution networks, it would, above all, belong to small and medium-sized enterprises. The current non-interactive development model does not allow the development of these activities and a more equitable distribution of world wealth.

SPAWHE significa Sinergic Plants, Artificial Welling, Hydroelectric Energy. Unfortunately, on planet Earth, today there is no synergy between anthropogenic plants which are all mono-thematic, since science works watertight compartments and also industry does the same, marketing incomplete fixed and mobile plants. The present man-made plants are only fossil, biological, nuclear, solar, wind power; they only purify the water, or filter the air. The current centers of world power pretend not to understand the importance of interactive synergies, although they have been clearly published by myself. Interactive systems have nothing to do with the current way of designing thermal power plants, purifiers, digesters, desalination plants. They can be mainly energetic with depurative side effects, or mainly purifying, with energetic side effects. In the sense that they would be autonomous energetically to perform purifying functions. This could be the case of large limestone greenhouses where the great pollution of fumes, dust and $\mathrm{CO} 2$, produced by high furnaces, incinerators and thermal power plants, which obviously cannot have the current production capacities of steel, energy, waste incineration, if the purification cycles that have not closed so far must close. In fact, for example, the sustainable closure of the $\mathrm{CO} 2$ cycle can only be done by making cold water react the raw limestone material and the $\mathrm{CO} 2$ that must be captured and concentrated specifically in greenhouses. Calcium reaction mechanisms are erosion reactions. The reaction mechanism for carbon erosion is: $\mathrm{H} 2 \mathrm{O}+\mathrm{CO} 2->\mathrm{H} 2 \mathrm{CO} 3$ (carbonic acid). In addition, $\mathrm{CaCO} 3+\mathrm{H} 2 \mathrm{CO} 3->\mathrm{Ca}(\mathrm{HCO} 3) 2$ this compound is calcium hydrogen carbonate (calcium bicarbonate). If we do not produce this cold reaction we have the opposite effect to the reduction of $\mathrm{CO} 2$ because we have to use calcium oxide whose production takes place by calcination of the calcium carbonate at $800-1000^{\circ} \mathrm{C}$, according to the reaction: $\mathrm{CaCO} 3$ + heat $\rightarrow \mathrm{CaO}+\mathrm{CO} 2$ this reaction involves the emission into the atmosphere of $1.57 \mathrm{~kg}$ of $\mathrm{CO} 2$ for each $\mathrm{kg}$ of $\mathrm{CaO}$ produced based on the molar weight, plus the $\mathrm{CO} 2$ emissions due to the fuel used. The limestone greenhouses, inserted above or in the vicinity of the water purification pits, in addition to producing carbonates in the water, would also have knocked down Sox and Nox, producing sulphates and nitrates, and knocked down the poor more or less thin, which aggravate lung disease and 
exponentially increase coronavirus deaths.

Patent office's cannot speak lightly of "perpetual motion" with the poor scholastic knowledge they possess on the subject, because world science is guilty of not having deepened the interactivity between the physical characteristics of water and air, as did the undersigned, both in submerged hydroelectric plants, both in those with water recycling at atmospheric pressure, and in those pressurized with compressed air. This is the real reason why in the world databases of patent deposits these applications do not exist. This does not mean that they cannot be realized by changing the way of designing the systems and above all by modifying the pumps. Much of global warming is due precisely to this trivial mistake of world science. Patent offices should only be limited to registering the filing dates of patent applications because they do not have the scientific knowledge to go further. I do not say this to be offensive to them, but I myself realized the interactive possibilities only after forty-five years of work experience. However, even for other reasons the whole patent system must be modified, completely separating industrial and intellectual property with copyright, to which inventors aspire like the undersigned who deal with inventions of public utility, inexplicably hidden from the centers of world economic power.

With the planet warming up and the oceans becoming acidic, the calcareous greenhouses that have never been built, should have already been obligatory to fight these two interconnected global phenomena, also supporting the significant energy costs that would result without the invention compressed hydroelectric energy, which miraculously, this cost would reduce to zero. The calcareous greenhouses would have been better than the C. C. S. system (carbon, capture, and storage) experimented without success and with very high costs (at least fifty billion dollars) from world public science. But no one wanted the simplest and most powerful energy in the world by making legally (so to speak) the inventions and copyrights of dozens of patents legally deposited by a simple pensioner.

If world silence continues, the French European revolution, the American war of war, the peaceful one of Gandhi in India, the cultural war and that of Tien and Men in China have been in vain. The main advantage of combining limestone greenhouses with compressed hydroelectric energy is the fact that the same water that produces energy, purifies the fumes, recovers the $\mathrm{CO} 2$ to produce alkaline waters, and recovers much of the steam produced, which is condensed by contact with the metal wall of the roof of the cooled building, having an acid $\mathrm{PH}$ (5.5) it cooperates to corrode the calcareous material that reacts chemically with the $\mathrm{CO} 2$, equally acid (5.5), in the rains purifying the fumes.

The real reason why the patent offices reject the patent applications of private inventors is due to the fact that the search for international precedence is not made by the Italian patent office, but by the European Patent Office. The Italian State must pay the sum of approximately 1,200 to the European bureaucracy for each patent filing for which this type of research is carried out.

In fact, the world's incompetent legislators have created these procedures that force Patent Offices to cut on the amount of patents to be examined. Unfortunately, it cuts in the wrong direction, which prevents the search for sustainable development and the protection of the environment. The global and Italian research bodies have adapted to this system and develop patents for technical and scientific support attractive to the private industry that have nothing to do with protecting the environment. In fact, if the Italian public design bodies had patented the solutions that the undersigned filed, their only customers would have been antagonized. Having the Italian state renounced being an entrepreneur, like most of the world governments, which are multinationals. All this is perverse and immoral because the collaboration between controllers and subsidiaries has been legalized and no one can afford to study sustainable and rational environmental solutions such as limestone greenhouses that should be flanked by every global thermal system, any size, together with other systems, such as the smokestacks that capture the fumes, partially purify them and convey them to the subsoil, making them rise towards the atmosphere, passing through the limestone greenhouses.

If we do not understand the possible synergies between sustainable energy and purification cycles we cannot create an alternative development model to the current one that has been blocked by a very small virus because man has separated from nature by closing himself in the cities with skyscrapers and millions of inhabitants but above all, he has not been able to develop interactive purification and energy projects to protect the environments in which he lives. It is ridiculous to wait for the rains to lower the percentage of fine dust in the atmosphere, but it is even more ridiculous that the world ruling class has not noticed that correctly proportioning fossil energy plants and carrying out complete cycles would have simultaneously eliminated $\mathrm{CO} 2$ and fine dust with an urban atmosphere. It is even more ridiculous that studying the way to save energy to clean fossil energy, it has not identified compressed hydroelectric energy, which is the only terrestrial energy that does not consume fuels, electrodes, radioactive materials, or photovoltaics. It simply borrows the air whose pressure it statically exploits and the water, which it uses as an energy vector in a more intelligent way than the thermal gases, which are less powerful for the same pressure flow, being the density of the water, almost a thousand times higher than that of gases. In addition, neglected energy systems can circulate pressurized water at room temperature without dispersing either the volumes of water or the volumes of air and produce clean and powerful energy that without intermediate, chemical or thermal passages can feed electromagnetic currents of electric motors that develop the motor torque, and with this feed the Newton's thrust, or induced currents that develop the Lorentz linear thrust. Obviously, if we add these two thrusts in the transport decks we can move in a three-dimensional space, if necessary, also opposing the gravitational force. So we have to redesign all means of global marine and space land transport. Above all, we can restore and protect natural environments 
from above, without crossing them with railways and tunnels. Above all, from above, we can immediately intervene to block the outbreaks of fires that are destroying the natural habitat that nature has preserved for billions of years in a perfect biological balance, without viruses such as coronaviruses being able to escape from the natural environment.

I think that if Leonardo da Vinci had lived in our time, he would not have wasted time studying aerodynamics, as evidenced by his notes deposited in museums, because he would have realized that it is not enough to fly in the atmosphere to overcome great distances between countries and continents. It is also important, do not pollute the atmosphere, and stop in flight to be able to extinguish the fire outbreaks before they spread undisturbed, as happens every year in all countries of the world. He would have noticed that aerodynamics does not allow stopping, while the principles developed by Maxwell, faraday, Neumann, Lenz, Lorentz, combined with those Newton, Pascal, Torricelli, Venturi, could have allowed it. Unfortunately, science is not very creative, for these reasons there is a need for inventors who combine scientific principles and technologies.

The real cultural pandemic began with the advent of the industrial era, when heat and other mono-thematic energies were chosen, without investigating the interactive energies that would protect the environment, instead of polluting it. These choices in just over a century, in addition to creating environmental disasters and huge public debts (to create large public works that are not needed, because energy can be produced in every corner of the earth in the instant it serves) have also destroyed the biodiversity, which have made us more vulnerable. However, world leaders are allocating thousands of billions to fight individual viruses through medical research and to find social safety nets, so that entire countries can be quarantined, waiting for the virus on duty to make its victims and pass on to others. countries, destroying not only human lives but also the economy Among the thousands of billions allocated by the various countries against the covid-19, a penny of any world currency has not yet been allocated to change the development model, which obviously should start from experimenting with interactive energy, between water and air, which is the only one that would protect the environment and human health by dissolving oxygen in the water as a secondary effect of the production of electromagnetic energy, which could be produced in every corner of the earth. Even in the chest of the elderly man by means of the artificial heart oxygenator of the blood. In fact, the solution that would help the planet Earth to defend itself from global warming, suitably miniaturized, would also help man to restore the immune defenses caused by aging cells.

Italian politicians have believed they are being smart by selling ILVA to an Indian multinational, which certainly has not made a commitment to add immense limestone greenhouses to the high ovens to close all open cycles. There are almost certainly no spaces to do so, unless the factory is divided into several factories distributed differently across the territory.
But the serious thing is that those who have treated ILVA's environmental problems do not even know what calcareous greenhouses are and how they work. They should take advantage of this period when covid-19 forces them home to read this article and previous ones that deal with this topic, because the IILVA topic will only end when the proposed solution of the undersigned is realized, which is the only one sustainable, especially after the last update that transforms the greenhouses into a submerged hydroelectric plant that cleans the fumes and dust producing electricity, instead of absorbing it. Patent offices, which have learned by heart in world schools that energy is not produced from nothing, also consider compressed air as nothing. Probably also their professors, because there has been no worldwide debate on these subjects. But it is science that does not want to speak. Not the undersigned, who knows their job.

This ruling class demands sacrifices from the people at crucial times, but spends no resources on experiencing global sustainable work. Governments are governed by the world's economic centers of power that have produced global warming. There is no scientific and technological opposition to world power centers. In today's society, since no one exists that designs anthropogenic plants globally, only technologies can be improved, which are already at a fairly advanced level. There are no independent inventors from public and private employers who are able to reason without partisan interests, scientifically and globally analyzing the cycles of the machine and systems, modifying both of them, without accepting the emission limits, which have accepted the current world scientific commissions. Only by interactively designing the plants can targets with zero emissions be achieved. SPAWHE has shown that the more compressed hydroelectric energy we produce, the more we will protect the environment, moreover, without paying for fuel, radioactive or electrolytic materials. The world ruling class and its consultants have opposed only silences. Now this ruling class calls us together to fight against the tiny and invisible covid-19, risking to lose their lives, privacy and economic well-being. We must keep social distances also with the people we love. This war is making many innocent victims. As in all wars, those who fight and those who die do not know the real reasons why the war broke out. Not even the undersigned knows the real reasons for this war, but he has fought it for long before it was declared. Since 2006, when he retired, he has been fighting, like Don Quixote, without even a squire and without any public and private funding, proposing an alterative development model, based on purification and interactive energies. Which not only can defeat global warming, it can also restore natural biological balances, since we do not need any type of fuel to create heat, cold, food and transport men and goods. So, we don't need to deforest the woods. Much of the food of the future will be produced with "ARTIFICIAL WELLING", simultaneously fighting oceanic acidification.

Only by scientifically applying the rules of work organization globally can we avoid corruption and ignorance that prevents progress, because we are forced to always choose the best and 
most up-to-date solutions. One is the best overall solution for energy and purification development. If there are discrepancies between one country to another, it means that not everyone has updated the state of the art perfectly. Today we are at year zero of purification and interactive energies because all governments and the United Nations themselves tried to hide their mistakes, thinking that they would never be discovered by anyone. In fact, it was not easy to identify them. This is demonstrated by the fact that I spent a lifetime of work and still I am not believed by anyone. All guilty no guilty.

As they say: "mens sana in corpore sano". This applies both to protecting the environment and the human body, especially when it has aged. I'd like to know how the covid-19 would react, every time it would go through the small pressurized autoclaves to a bar $(750.95 \mathrm{~mm} \mathrm{Hg})$ which would replace the left and right ventricles of the old men of the future (including myself, already seventy-one) and immediately after passing through the mini turbines that lower the pressure to normal values for human activities $(120-180 \mathrm{~mm} \mathrm{Hg})$ to supply the systemic or pulmonary circuit. Probably, the old people will not need lung ventilation; they will not have heart attacks and will never lack oxygen to the brain. They will be able to continue to protect their children and grandchildren, as they have always done. Don't be a burden on the society of the future. It will only be a question of spare parts, but without altering human DNA. And to create a more efficient and provident society that knows how to protect men and the environment at the same time.

The undersigned, after seeing that neither the multinationals nor the world public bodies want to close the cycles that open, has borrowed the air and water from the environment, returning them with the same chemical composition after feeding without production of heat the electromagnetism of current generators or electric motors that produce linear torque or thrust. We don't need other forms of primary energy because nothing can cost less than water and less than air, which can be used with almost infinite static pressures. In fact, compressed air to produce energy must exert its one-way pressure, such as gravitational force. But locally, gravitational force can overcome, by circulating one-way water and with this feed turbines that feed current generators and consequently, motors with drive torques and linear thrusts, which together, as mentioned, can overcome the gravitational force. The key to this universal mystery is the pump with the double separate power supply up to the impeller, which, by allowing the pressostatic equilibrium in the pump body, also allows the recovery of the water that produced the electricity through the turbine and the generator of current. Therefore, we can produce energy indefinitely by always recycling the same water and the same amount of air. Although this partially dissolves in the water in proportion to the pressure, it exerts on the water (obviously by purifying the water or human blood). But the quantity of absorbed air is returned to the environment at the turbine outlet, therefore, it can be sucked, compressed and inserted again in the air cushion of an autoclave that feeds the entire system indefinitely, not on the basis principles, thermodynamic, chemical, electrolytic, but based on the very simple principle of impenetrability of bodies: In fact, in the pressurized autoclave, we can introduce in low pressure, through the second pump supply, only the same amount of water that passes through the turbine, while the same pump with the main power supply continuously recycles the pressurized water inside the autoclave, balancing the inlet and outlet pressures from the impeller and consequently, allowing the entry of the same amount of water that came out through the turbine. In fact, no more water can enter than that which came out, precisely because of the principle of impenetrability of the bodies, unless we introduce the water with a pump that has a head higher than the pressure of the autoclave air cushion. It would be very foolish to consume energy by using a high-pressure pump to overcome the internal pressure of the autoclave, while we can get around it by modifying the recycling pump that works with a very small head and a very small absorption of energy. Yet we have made this mistake in all world plants since the advent of the industrial era and we do it even when we raise the waters to the reservoirs to distribute it by gravity from the piezo metric towers. It would be enough to insert the water to be raised in the recycling circuit of the upper basin to save, this immense amount of energy that we waste all over the world and even produce energy with the pressure of the recycled water.

Those who want to go down in history, as a statesman, cannot do so only by allocating the highest sum to cover the expense, but also by choosing the plans for future development. Of course, it will go down in history that it will first find the covid-19 vaccine. Not those who will prevent these viruses from developing in the future. I am happy to work for this purpose. But, at least, I would like to know from this political and scientific ruling class the reasons for their silences? Did they give the delegation of Italian world scientific authorities at the Patent Office that has declared my patents in most cases "perpetual motion"? I think that in the interest of future generations, these absurd concepts must be clarified. Those who teach in schools cannot transmit to young people only partial truths, such as the principles of energy conservation, neglecting to teach interactive principles that are much more important, as they teach how to save energy in a process phase and to multiply it at a later stage, bringing together principles, especially different physicists. I am sure I am not wrong and I know that the eye also wants its part. Unfortunately, with my modest grasp I cannot afford to experiment. For this reason, in the latest publications I have proposed to set up a joint-stock company called SPAWHE S.P.A. with the function of an experimenter body, which shares with the inventor the intellectual copyrights that today are not recognized to inventors who do not find financiers. History cannot recognize these rights after the planet and humanity have suffered irreparable damage.

If governments, the United Nations and their scientific advisors believe they are right, continue with their silences and the current development model and face the judgment of history. Some of the following articles published on my website have been published by major magazines, but for myself, it is important that they are all together on my website to 
demonstrate that true sustainable development does not want it, neither governments nor multinationals. They probably don't want to admit the mistakes they made. I personally do not look for culprits but only that the right things are done in the right place at the right time, applying the development of the real state of the art, but also experimenting with the virtual one, proposed, not by competition, but by an impartial inventor, who he gave up job offers in order to develop his energy and purification solutions without conditioning, after spending a whole working life installing industrial and environmental systems, designed by industrial and environmental designers without adding the two experiences together. It is the sum that makes the difference because the current industrial plants lack the synergistic environmental and energy experiences and the environmental plants, both the energy and environmental synergies, and the scientific organization of industrial work that multiplies the returns are missing [1-50].

\section{References}

1. http://www.spawhe.eu/development-and-theenvironment-penalized-by-science-and-internationallaws/

2. http://www.spawhe.eu/the-world-public-debt-fraud/.

3. http://www.spawhe.eu/artificial-heart-oxygenator-ofblood-energyically-autonomous/

4. http://www.spawhe.eu/compressed-air-is-much-morepowerful-and-economic-of-hydrogen/.

5. http://www.spawhe.eu/after-the-failure-of-cop23/.

6. http://www.spawhe.eu/cop23-the-unthinkable-hasalready-been-thought-with-interactive- energy/.

7. http://www.spawhe.eu/cop-23-the-mysteries-of-theinteractive-energy-and-depurations/.

8. http://www.spawhe.eu/the-force-of-rational-scientificglobal-reasoning/.

9. http://www.spawhe.eu/if-science-was-globally-applied/.

10. http://www.spawhe.eu/learn-to-extract-better-energyfrom-the-environment/.

11. http://www.spawhe.eu/a-new-development-model-withinteractive-energy/.

12. http://www.spawhe.eu/open-letter-of-denunciation-tocourts-of-international-justice/.

13. http://www.spawhe.eu/second-open-letter-ofdenunciation-to-courts-of-international-justice/.

14. http://www.spawhe.eu/aerospatial-pressurizedhydroelectric-transport-system/.

15. http://www.spawhe.eu/fighting-global-warmingextending-the-borders-of-perpetual-motion/.

16. http://www.spawhe.eu/the-potentialities-of-pressurizedhydroelectric-energy/

17. http://www.spawhe.eu/defend-the-environment-and-theterritory-by-producing-energy/

18. http://www.spawhe.eu/cop22-failed-international-crimeof-states-not-punished/

19. http://www.spawhe.eu/the-pressurized-submergedhydroelectric/

20. http://www.spawhe.eu/hydroelectric-power-auto-withtorque-peripheral-to-the-wheels/
21. http://www.spawhe.eu/sustainable-desalination/

22. http://www.spawhe.eu/the-energetic-miracles-of-pumpswith-separated-double-supply-until-to-the-impeller/

23. http://www.spawhe.eu/the-sustainable-future-ofenvironment-energy-food-and-labour/

24. http://www.spawhe.eu/where-is-the-science-and-wherehope/

25. http://www.spawhe.eu/causes-of-failure-cop-21/

26. http://www.spawhe.eu/from-efficient-purification-tosustainable-energy/

27. http://www.spawhe.eu/the-reasons-of-lack-protection/

28. http://www.spawhe.eu/the-role-of-biological-energy/.

29. http://www.spawhe.eu/energy-right-at-the-right-time/.

30. http://www.spawhe.eu/european-environmentalcompetition/.

31. http://www.spawhe.eu/about-us-curriculum-vitae/.

32. http://www.spawhe.eu/closing-the-anthropogenic-carboncycle/

33. http://www.spawhe.eu/expo-2015-and-spawhe/.

34. http://www.spawhe.eu/initial-presentation-of-spawhe/.

35. http://www.spawhe.eu/who-govern-the-world-thesovereign-states-or-the-world-bag/,

36. http://www.spawhe.eu/ SOMEONE IN THE WORLD SHOULD PROHIBIT THE INCOMPLETE INVENTIONS OF SCIENCE.

37. http://www.spawhe.eu/cop24-the-replies-that-missto-greta-thunberg-yellow-gilets-poor-countries-andsustainable-inven/

38. http://www.spawhe.eu/the-omission-crime-is-the-dailybread-of-sciences-bureaucrats-and-world-governments/

39. http://www.spawhe.eu/the-lost-civilizations-einstein-sthought-and-survival-energy/

40. http://www.spawhe.eu/7th-international-conference-onearth-science-recycling-space-technology-rome-italy-2223-may-2019-novit\%C3\%A0/

41. http://www.spawhe.eu/the-global-warming-has-beenproduced-legally/

42. http://www.spawhe.eu/who-will-win-the-race-to-themiraculous-energy/

43. http://www.spawhe.eu/environmental-projects-andreplies-of-a-false-general-secretary-of-the-un/

44. http://www.spawhe.eu/against-the-inefficiency-of-theunited-nations-and-governments-even-the-obed-ofwidow-may-be-useful-to-protect-the-environment/

45. http://www.spawhe.eu/aerospace-and-submarinetransport-system-with-global-interactive-primary-andinductive-linear-motors/.

46. http://www.spawhe.eu/flying-and-floating-cars-withinteractive-global-linear-motors-and-thrust-of-newtonand-lorentz/.

47. http://www.spawhe.eu/a-global-stock-company-againsterrors-omissions-and-opportunities-wasted-by-scienceand-world-power-centers/

48. http://www. Spawhe.eu/THE-WORLD REVOLUTION OF TRANSPORTATION UNWANTED BY MANUFACTURERS, BY SCIENCE BY THE GOVERNMENTS AND OTHERS.

49. http://www.spawhe.eu/open-letter-to-the-patent- 
office-and-the-italian-government-in-the-time-of-thecoronavirus/

50. http://www.spawhe.eu/we-will-not-get-rid-ofcoronaviruses-without-creating-a-true-sustainabledevelopment-model/. 